\title{
Deciding together: a BIM-based platform for participative design processes
}

\author{
Juliano Veraldo da Costa Pita \\ Instituto Federal de São Paulo (IFSP) e Instituto de Arquitetura e Urbanismo da \\ Universidade de São Paulo (IAU-USP) | Brasil | juliano.pita@ifsp.edu.br
}

\author{
Marcelo Tramontano \\ Instituto de Arquitetura e Urbanismo da Universidade de São Paulo (IAU-USP) | Brasil | \\ tramont@sc.usp.br
}

\begin{abstract}
This article discusses aspects of building a digital platform that allows non-technical actors to participate in the development of the design of public facilities using BIM. The concept of the design of such a platform refers to characteristics specific to BIM, aiming at an equivalence between the contributions of non-technical and technical actors to the process. We have developed a platform prototype and studied its adaptation to different applications. The article discusses the construction and testing of the different versions and the preliminary results of performance tests.
\end{abstract}

Keywords: BIM; Participatory processes; Public facilities.

\section{INTRODUÇÃO}

Há, no Brasil, uma crescente adoção do uso do BIM (Building Information Modeling) na indústria da construção civil, tanto nas etapas de projeto como no gerenciamento e na operação e manutenção, até o descarte ou readequação da edificação para outros usos ou contextos (Kassem e Succar, 2017). Esta adoção possui, inicialmente, um caráter individual, ou seja, os responsáveis pelas mudanças de processos são os próprios atores envolvidos no processo produtivos destas obras, o que torna o processo heterogêneo tanto entre os diferentes campos quanto internamente a estes (Succar, 2009). O papel específico de cada ator já foi discutido exaustivamente por Succar e Kassem (2015), Wong, Wong e Nadeen (2009) e Cheng e Lu (2015), e dentre todos, o poder público é um dos atores mais relevantes no processo.

Cheng e Lu (2015), em especial, enfatizam que o papel do poder público é múltiplo e central no processo de adoção, pois, além da responsabilidade regulatória inerente ao Estado, ele atua contratando a construção de edificações (essenciais para a prestação de serviços à população e muitas vezes carregadas de forte papel simbólico), a elaboração de estudos e planos, e também promovendo e incentivando o treinamento de profissionais através de suas instituições de ensino e pesquisa. Atua também no campo das tecnologias, através de pesquisas desenvolvidas ou financiadas pelo poder público, e no desenvolvimento de infraestrutura adequada.

Neste aspecto, o poder público adota o BIM pelas mesmas razões que levam todos os atores envolvidos na indústria a fazê-lo, como a mitigação da fragmentação existente, má coordenação entre projetos e questões de transmissão de informação (Aibinu e Papadonikolaki, 2016), além de motivos que refletem as particularidades do setor público, como a transparência, impessoalidade e responsabilização solidária dos atores envolvidos nos processos licitatórios e no gerenciamento dos contratos.(Ciribini, Bolpagni e Olivieri, 2015).

No Brasil, a produção de edificações públicas ocorre majoritariamente através da execução direta pela administração pública ou através da contratação de projetos e obras com a iniciativa privada. O arcabouço jurídico que dá embasamento a estas contratações encontra-se na Lei 8.666, de 1993 (Brasil, 1993), responsável por ordenar todo tipo de contratação efetuada pelo poder público. Esta lei é bastante generalista e prevê uma separação clara entre as diferentes fases de execução contratual em projeto, execução e ocupação, além de impedimento legal do envolvimento do responsável pelo projeto na construção, a não ser como consultor. Este modelo de licitação é conhecido internacionalmente como design-bid-build (projetar-licitarconstruir) (Ciribini, Bolpagni e Olivieri, 2015). Esta forma de contratação impõe um grande peso à qualidade e precisão do projeto: omissões, erros e alterações posteriores, consequência de problemas nos estudos de viabilidade e na compreensão das demandas, são responsáveis por grande parte dos aumentos de custos, prazos e na inadequação posterior das edificações (Melhado, 2001). Estas questões também possuem um impacto grande na qualidade da obra e na transparência do processo produtivo como um todo, já que o projeto é efetivamente o componente legal que explicita as obrigações dos contratados posteriores e que baliza a fiscalização dos contratos.

Infelizmente, a já citada Lei 8.666/93 é bastante vaga nos pré-requisitos para o início do processo de licitação de um serviço qualquer, exigindo somente a existência de um "Projeto Básico", que não encontra definição clara nas normas técnicas que regram a existência dos demais documentos indispensáveis aos projetos. Na referida lei, o 
projeto básico é definido através do uso de expressões vagas como "adequado", "suficiente" e "possibilite". Este grau de indefinição prejudica não somente o andamento do processo de contratação e execução da obra, mas também a própria prestação de contas e frustra qualquer tipo de iniciativa de transparência efetiva.

A transparência é uma questão muito delicada quando se trata de obras públicas. Ela não se refere somente à publicização das decisões do poder público, mas ao envolvimento da população em todo o processo, conforme preconizado pela Carta Magna em vigor. Assim, um bom projeto para uma edificação pública não deveria somente atender critérios técnicos, como grau de detalhamento, compatibilização, levantamentos precisos e confiáveis. É também necessária publicidade e envolvimento dessa comunidade nos estudos de viabilidade, alocação de recursos no orçamento público, regularização de pendências jurídicas, desapropriação de terrenos, além dos estudos que justificam a implantação de determinado equipamento público e embasam o programa específico da edificação (Pita, Tramontano, 2017)

Esta ausência de informação contida nas peças de planejamento também favorecem a corrupção, já que as incertezas em seu cerne se configuram em falta de informação que, futuramente, será necessária para que se efetivamente a contratação e a edificação seja produzida. O controle e a posse dessas informações ficam a cargo exclusivo de indivíduos inseridos na estrutura administrativa governamental, gerando um monopólio do fluxo informacional em alguns agentes. Estes grupos políticos utilizam a capacidade de indicação a estes cargos como moeda de troca para apoio à pautas governamentais nas casas legislativas, efetivamente tomando posse de parte do orçamento público. Esta estrutura é típica do presidencialismo de coalizão em vigência no Brasil, e repete-se em todas as esferas de poder: federal, estadual e municipal.

Assim, retornando ao ponto inicial, podemos afirmar que somente ações em várias frentes são capazes de mitigar os problemas observados nas obras públicas. Nesta pesquisa nos ocupamos de duas questões fundamentais: o do uso do BIM como veículo de melhoria da qualidade e das definições das peças de planejamento que embasam a contratação e execução de obras públicas e a disseminação ampla e o envolvimento direto, desde o princípio, das comunidades interessadas no desenvolvimento na edificação. Além dos efeitos sobre a corrupção, a pesquisa também indica que pode haver a introdução de novos dados no processo de projeto que de outra maneira não estariam presentes, podendo gerar novas soluções para o problema colocado, com efetiva apropriação da comunidade envolvida.

\section{BIM COMO PLATAFORMA DE PARTICIPAÇÃO}

Em sua própria definição, o BIM é uma plataforma digital colaborativa (Eastman et. al., 2008), tendo em mente a interação e a integração entre os diferentes setores e atores envolvidos no processo produtivo de um projeto. Esta interação se dá através do deslocamento do fluxo informacional dos indivíduos para a própria plataforma, que se encarrega a de manter um entendimento unificado entre todos os envolvidos.
Estudos anteriores (Pita, Tramontano 2017 e 2019) indicam ser possível e desejável associar as questões de participação, meios digitais, eficiência e transparência através do uso da plataforma BIM, permitindo um maior controle social por parte da comunidade interessada.

Entretanto, há questões que devem ser consideradas nesta aplicação. Mesmo com uma diminuição da carga interpretativa e descentralização das informações com o gerenciamento pela plataforma, o acesso a este conjunto de informações é realizado através de plataformas voltadas aos profissionais da área, exigindo um conhecimento técnico mínimo para a total compreensão e manipulação dos dados contidos no modelo central, conforme pesquisas elaboradas anteriormente pelo grupo de pesquisa Nomads.usp.

Quando voltados a facilitar o acesso à informação, estes aplicativos o fazem através de uma via de mão única: o usuário é encarado como receptor da informação, mas não necessariamente como produtor dela - a não ser através da mediação de um técnico. Dessa forma, há um desequilíbrio entre a capacidade de agência dos atores técnicos e não técnicos. Em um ambiente de discussão pública, este desequilíbrio não deveria ocorrer, já que a igualdade de influência é elemento essencial da participação pública. Corre-se o risco de que, caso contrário, a comunidade seja reconduzida a unicamente chancelar soluções pré-definidas, sem poder efetivamente contribuir com novas informações. Este processo é normalmente associado ao atual formato das audiências públicas, onde não há o intuito de se coletar subsídios, mas de se obter a chancela popular a uma solução de cuja formulação a população não participou.

\section{PRÉ-REQUISITOS DA PLATAFORMA}

Assim, a pesquisa caminhou no sentido de elaborar prérequisitos e efetivamente construir uma plataforma capaz de atendê-los. São os seguintes:

1- A plataforma deve permitir acesso ao conjunto de informações utilizadas no desenvolvimento do projeto; no caso do BIM, este conjunto está contido no modelo central, e, portanto, a acessibilidade total a este é prioridade;

2- A plataforma deve dar condições para que as discussões ocorram em igualdade de condições ao mesmo tempo que preservam as atribuições específicas de cada ator. Esta equivalência de importância não significa substituição de atribuições, mas sim que todas as informações devem ser incorporadas à discussão de maneira neutra e com a mesma relevância a partir da função ou ponto de vista específico do ator;

3- A plataforma deverá permitir a acessibilidade plena às informações contidas no modelo. Isso significa que, além de prover estas informações, estas devem estar categorizadas e processadas de forma a exigir o mínimo possível (e, idealmente, nenhum) conhecimento técnico para ser compreendidas;

4- A plataforma deverá ser desenvolvida sob licenças de código aberto, permitindo que futuramente seja adaptada e modificada para fins correlatos. Da mesma forma, onde possível, ela deverá se utilizar de outros códigos cujas 
licenças sejam livres e abertas, para assim permitir pleno acesso e distribuição futuros sob as mesmas licenças.

Dessa forma, ficou claro que haveria necessidade de se permitir o acesso da equipe técnica envolvida ao mesmo modelo de trabalho e estudo, a partir do mesmo repositório de trabalho, onde exista um sistema de versionamento e atribuição de alterações aos diferentes atores. Esse sistema ficou a cargo do Bimserver (https://github.com/opensourceBIM/BIMserver).

Bimserver é executado em uma máquina servidor, disponibilizando as informações solicitadas pelos usuários sob demanda, eliminando a necessidade de se realizar o carregamento de arquivos grandes para as máquinas cliente, como é o caso do IFC completo. Além disso, o Bimserver possui interface gráfica de fácil utilização e sistema de versionamento e registro de revisões. Complementa a estrutura de backend (infraestrutura de suporte) o uso dos aplicativos Apache Tomcat 9 e o Apache 2 para utilização de aplicativos Java e serviço das páginas hospedadas no servidor, bem como o MySQL e PHP para armazenamento das informações sobre usuários e discussões, abrigados em um servidor Linux Ubuntu dedicado.

O desenvolvimento do frontend (interface com o usuário final) foi estruturado inicialmente em três versões cumulativas - 1.0, 2.0 e 3.0, onde os requisitos desta interface foram implementados e aprimorados. Estes requisitos são:

1. permitir a visualização de um modelo tridimensional BIM fora do ambiente BIM, incluindo suas versões atualizadas;

2. possibilitar a associação de comentários de usuários a partes ou elementos do modelo, através de poucos cliques;

3. utilizar linguagem textual e visual acessível a nãotécnicos, didática e próxima do coloquial;

4. aceitar a inclusão de conteúdo textual e fotográfico nos comentários;

5. permitir a visualização da totalidade dos demais comentários postados, para que toda pessoa que insira comentários possa ler todos os comentários postados anteriormente;

6. estimular o debate, permitindo que se comente em comentários de outras pessoas;

7. permitir que os comentários sejam vistos pela equipe técnica, tornando obrigatória uma resposta aos comentários;

8. permitir que atores não-técnicos comentem as respostas dos atores técnicos;

9. permitir simulações orçamentárias para subsidiar novas sugestões de projeto;

10. implementar um sistema de "apoiar" ou "desapoiar", comentários e tópicos individuais.
Pretende-se que os não-técnicos possam introduzir informações e questões próprias de seu universo de conhecimento, ou seja: questões locais, reivindicações anteriores, sentimentos da comunidade, relações com elementos da paisagem ou a experiência cotidiana daquele determinado contexto urbano e social, dentre outras. Neste momento, há uma ampliação da equipe de projeto para englobar os atores não técnicos, e não somente consulta à comunidade. Para tanto, propõe-se que a discussão ocorra por tópicos e por sucessivas aproximações ao objeto, com progressivo aumento do grau de detalhe, e de tomadas sucessivas de decisão. Além de contribuir para uma mais fácil introdução da plataforma nos processos produtivos existentes, esta definição pode auxiliar o envolvimento da comunidade por tornar mais acessíveis as informações a ser processadas e consideradas nas tomadas de decisão. Além disso, este processo paulatino, no contexto brasileiro, pode auxiliar a construção de um conhecimento coletivo progressivo sobre o funcionamento da administração pública, fomentando o interesse do cidadão.

Atualmente, a plataforma está em sua segunda versão, incorporando diversas revisões frutos dos testes realizados na primeira versão. Estes testes, além fornecerem subsídios para o aprimoramento da plataforma em si verificaram a viabilidade técnica e prática de seu uso para os fins pretendidos.

\section{TESTES E REVISÕES}

A fim de testar as funcionalidades e navegabilidade do aplicativo com indivíduos não-técnicos e externos ao processo da pesquisa, conduzimos um primeiro experimento de abrangência reduzida - usualmente chamado de pré-teste -, contando com um grupo de seis pessoas de diferentes faixas etárias e gêneros. Seus resultados produziram uma listagem de ajustes, compreendendo diferentes graus de complexidade, e organizados nas categorias de 1. Acessibilidade, 2. Tutoriais e guias, 3. Adaptabilidade, (4) Segurança, (5) Ajustes visuais da interface, (6) Funcionalidades da interface, (7) BIM e IFC, (8) Divulgações e créditos e (9) Interface do administrador.

\section{PROJETO JAM!}

Um segundo experimento ofereceu a oportunidade de teste com uma comunidade real, tendo sido realizado no município de Viçosa, MG, no âmbito do projeto de pesquisa JAM!, em colaboração com o grupo de pesquisa Nó do Departamento de Arquitetura da Universidade Federal de Viçosa. Os ajustes necessários foram ordenados de acordo com a relevância e impacto de cada item nos objetivos do experimento, de maneira isolada.

Ao iniciar-se o processo de revisão, uma nova versão do aplicativo foi criada. Um exemplo de ajuste necessário foi a busca pela linearidade da navegação, identificada como essencial durante os testes iniciais. Enquanto a versão utilizada no primeiro teste propõe uma linearidade sutil, ainda utilizando páginas centralizadoras e exclusividade de ícones específicos para acesso às páginas, a versão utilizada no JAM! conta com uma proposta de navegação linear mais clara, com setas laterais, possibilitando o acesso a todas as páginas ao clicar nelas: anterior e posterior (figura 1). 


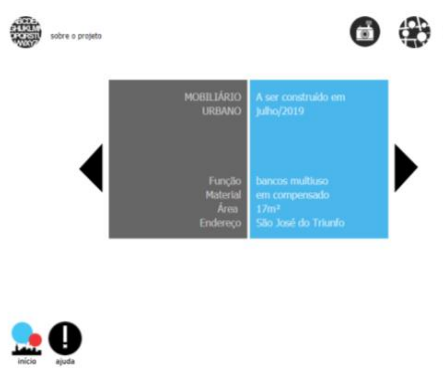

Figura 1: Página central de projeto da Versão 1 e página introdutória ao projeto da Versão JAM!, respectivamente. Fonte: os autores.

Uma alteração significativa, realizada apenas para o experimento com o projeto JAM! e posteriormente revertida, foi a supressão da necessidade de registro individual para navegação no aplicativo. Entende-se que o registro único e individual é indispensável para o uso do aplicativo em processos de obras públicas, como propõe seu desenvolvimento. Entretanto, para a aplicação prevista pelo projeto JAM!, o registro não cumpriria o papel previsto e talvez inibisse seu uso, retardando a ação. Em vista disto, foi decidido, juntamente com o grupo de pesquisa parceiro Nó da UFV, suspender esse registro para essa aplicação única, substituindo-o pela geração de nomes de usuário aleatórios. Esta decisão contribuiu para uma maior agilidade no uso da plataforma na dinâmica estabelecida pela equipe em Viçosa.

O uso do aplicativo no projeto JAM! constituiu sua primeira aplicação em um processo real de participação de atores não-técnicos no processo de projeto de uma proposta de intervenção urbana. O aplicativo não foi utilizado como meio exclusivo de interação entre a equipe técnica do projeto (composta pelos pesquisadores do grupo Nó) e a comunidade do distrito de São José do Triunfo, também conhecido como Fundão, em Viçosa. A interação no aplicativo ocorreu durante três eventos realizados no Fundão, nos dias 6, 7 e 8 de junho de 2019, assistidos pela equipe do Nó. Nos dois primeiros dias, o público foi composto por alunos da Escola Estadual José Lourenço de Freitas e, no terceiro dia, a interação ocorreu durante a festa junina da comunidade, com público mais amplo e variado. $\mathrm{O}$ aplicativo esteve aberto à interação durante todo o período, e foram registradas 65 contribuições distintas, já desconsideradas inserções duplicadas ou em branco.

Verificou-se que a interação com o aplicativo ocorreu exclusivamente durante o período em que os pesquisadores do Nó estiveram presentes com a comunidade, auxiliando-a. Devido à má qualidade da conexão à Internet no local, a livre navegação no aplicativo ficou prejudicada. Assim, houve somente a disponibilização de computadores do grupo com as páginas do modelo pré-carregadas, às quais os usuários foram direcionados após interagir com outras formas de apresentação do projeto, como maquetes físicas, desenhos técnicos e perspectivas impressas (figura 2).

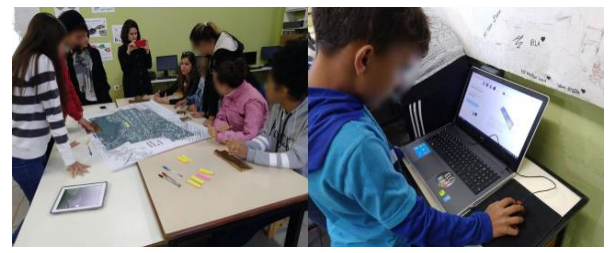

Figura 2: Projeto JAM!: número de contribuições distintas por dia de ação. Fonte: Igor Ambrósio Faria, Grupo Nó (2019).

A análise das respostas dadas pelos usuários revelou que os dois dias de ação nas escolas incentivaram maior quantidade de respostas acerca do objeto, seguidos de discussões sobre as questões mais gerais da comunidade, e, por fim, sobre o local e a situação da implantação do mobiliário projetado. Comentários gerais, sem relação direta com esses temas, superaram comentários sobre a implantação do projeto (figura 3).

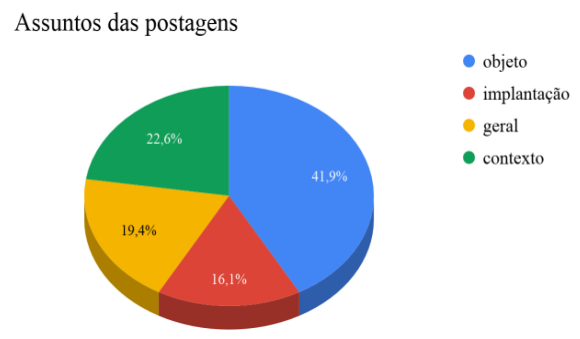

Figura 3: Distribuição dos assuntos dos comentários, durante toda a ação. Fonte: Os autores (2019).

O experimento mostrou que houve um entendimento do objeto proposto e um domínio sobre as informações oferecidas localmente. As opiniões sobre o projeto fundamentaram-se nos elementos presentes na ação presencial - maquetes físicas, desenhos, esquemas, representação tridimensional no aplicativo - enquanto as informações sobre o contexto local são próprias da comunidade e representam a contribuição única que esta comunidade específica pode acrescentar ao projeto. Não foram registradas colocações sobre o sistema ou o método construtivo do objeto.

O experimento no distrito do Fundão embasou novas reflexões que resultaram em novos ajustes no aplicativo. Talvez o retorno mais significativo tenha sido sobre a contextualização dos objetos nas imagens disponibilizadas ao público: se uma planta ou um corte são abstratos e de difícil interpretação, um objeto tridimensional ou a imagem de sua situação sem o contexto físico também pouco contribuem para o entendimento da proposta como um todo. No caso do material disponibilizado, verificam-se poucas indicações: os materiais que lidam com a tridimensionalidade do projeto (a maquete física e o modelo interativo do aplicativo) contêm informações somente sobre o objeto, sem seu contexto. A contextualização ficou a cargo das perspectivas renderizadas e impressas, apresentadas presencialmente durante a ação nas escolas, e das informações transmitidas oralmente pelos pesquisadores. 
O aplicativo mostrou-se dinâmico e responsivo, em especial na manipulação do objeto tridimensional, pois uma vez que o modelo IFC é carregado pela página, sua visualização fica a cargo da própria máquina do usuário. A biblioteca Javascript do webGL2 é satisfatoriamente otimizada para uso em computadores com poder de processamento mediano, o que tornou adequada a experiência.

As observações fornecidas pelos participantes das ações trazem contribuições relevantes para o projeto. A primeira delas é que se verifica uma aceitação, por parte dos participantes da intervenção: nenhum comentário ou colocação se posicionou contra a intervenção, e ficou evidente a preocupação com a conservação e com eventuais usos inadequados do equipamento proposto. Outra preocupação expressa recorrentemente nos comentários refere-se à segurança dos usuários: o modelo apresentava um objeto com grandes vãos entre as peças, o que gerou uma preocupação de acidentes ou de acúmulo de lixo. Por fim, outros usos foram sugeridos: rampa de skate, de bicicleta, local para observar as crianças brincando.

Em reunião de avaliação com a equipe do Nó após a ação, foi relatado uma grande dificuldade técnica no acesso à Internet no local, inviabilizando o uso mais autônomo do aplicativo por parte da comunidade. Essa dificuldade fo igualmente percebida através da existência de mensagens em branco ou duplicadas, pois a lentidão da rede local prejudicou o feedback ao usuário, incentivando-o a enviar novamente a mesma mensagem. A verificação automática de postagens duplas em curto período, bem como a impossibilidade imposta pelo aplicativo de publicação de postagens em branco, podem dirimir esta questão.

Estas dificuldades técnicas também afetaram o uso da plataforma em momentos posteriores à ação. Através da análise das estatísticas de acesso ao site e interação fornecidos pelo Google Analytics, e do script de tracking presente em todas as páginas, nota-se uma grande quantidade de sessões ativas no período anterior ao uso da plataforma, em consequência do próprio processo de desenvolvimento e testes, seguido de uma diminuição constante do interesse. Estas estatísticas indicam também um pequeno aumento no número de sessões utilizando terminais móveis após o evento, com pouca permanência. Isso indica uma necessidade de avanço na compatibilização da plataforma com o acesso a partir de celulares e tablets, e, em especial, a possibilidade de manipulação do modelo tridimensional a partir deles (figura 4).

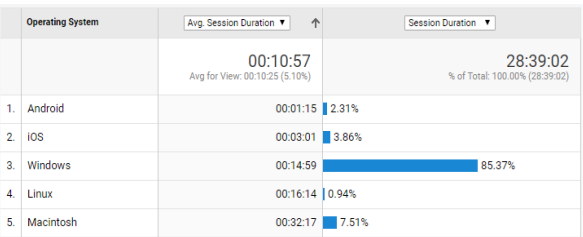

Figura 4: Sistema operacional utilizado para acesso ao site versus duração média da sessão. Notebooks e desktops possuem sessões mais duradouras. Fonte: Google Analytics (2019).
A próxima etapa do projeto está concentrada na produção do mobiliário proposto incorporando sugestões da comunidade obtidas durante a ação, e sua instalação no distrito do Fundão, no local definitivo.

\section{PELES CONTEMPORÂNEAS}

A exposição "Peles Contemporâneas" consistiu no projeto e produção de protótipos de sistemas de proteção solar de fachadas com o uso de aplicativos de modelagem paramétrica e posterior aplicação de processos de fabricação digital. Três diferentes protótipos foram projetados e construídos.

Foi realizada uma breve exposição com duração de duas semanas, exibindo as soluções encontradas ao público do Instituto de Arquitetura e Urbanismo da Universidade de São Paulo. As proteções foram colocadas no corredor de acesso para os ateliês da instituição, onde todos poderiam ver as proteções em pleno funcionamento.

Como forma de registro das impressões e análise dos observadores, foi utilizada uma nova versão da plataforma de visualização de modelos BIM. Foi criada uma versão específica para a exposição, contendo um texto breve sobre as proteções, os estudos de insolação, algumas imagens situando as proteções em fachadas de edifícios, além dos modelos digitais em si (figura 5).

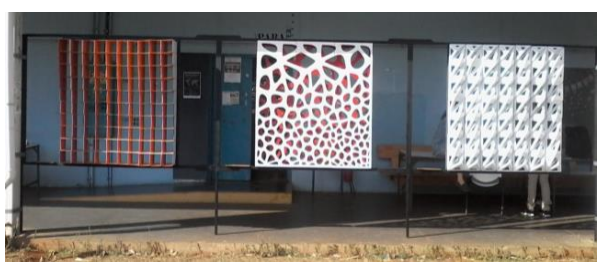

Figura 5: Protótipos dos sistemas de proteção em exposição. Fonte: Maurício Silva (2019).

Assim como no projeto JAM!, plataforma foi adaptada para ser utilizada de forma anônima. Outra característica que a diferencia da aplicação anterior é que não estava prevista assistência presencial no uso da plataforma, ou seja, o usuário deveria poder realizar as operações de maneira autônoma. A estratégia de divulgação incluiu a divulgação do evento através do Facebook para a comunidade da instituição, replicação de posts através das redes do grupo de pesquisa e divulgação direta, pessoa a pessoa.

Notou-se um grande número de acessos nos primeiros dias da ação (21 de agosto de 2019), com posteriores picos de acesso, e finalmente, pouco uso da plataforma. Este comportamento era esperado, já que se trata de uma exposição efêmera, que perdurou por pouco mais de uma semana. Outro mecanismo eficiente de divulgação foi o uso de QR code no local da exposição com link direto para a plataforma, como fica evidente na visualização das origens dos acessos (acessos diretos), tendo em segundo lugar, a estratégia de divulgação pelas redes sociais (figuras 6 e 7 ). 


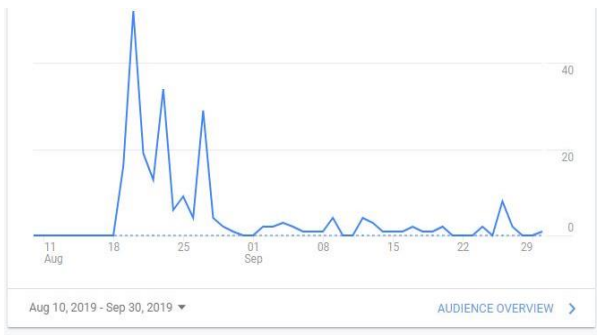

Figura 6: Quantidade de acessos durante o período da ação. Fonte: Google Analytics, 2020.

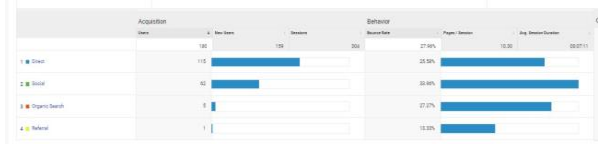

Figura 7: Origem dos acessos. Fonte: Google Analytics, 2020.

Entretanto, o sucesso na divulgação e análise não se refletiu em uma diversidade de interações na plataforma. Com efeito, foram contabilizadas somente 8 interações que não se traduziram em discussões, ou seja, foram somente postagens iniciais sem a ocorrência de respostas. Este é um contraste grande com o número de acessos únicos e pageviews, e foi objeto de observação posterior. A plataforma se comportou de maneira nominal durante todo o período do experimento.

\section{ÁTICO - APAE ITAPEVI}

O segundo experimento utilizando a plataforma foi realizado em colaboração com o Instituto Federal de São Paulo (IFSP), através do projeto de extensão de assessoria técnica para ONGs e entidades sem fins lucrativos - Ático Humanizar. Foi feito contato com a equipe com o projeto em andamento, em um momento de publicização das propostas à equipe interna da APAE. A plataforma, portanto, foi desenvolvida pensando-se em envolver os demais colaboradores neste processo, a partir de uma proposta já formulada. A APAE Itapevi atende mais de 400 alunos e seus responsáveis e possui por volta de 100 colaboradores, entre professores, voluntários, administradores e funcionários operacionais, constituindose em uma comunidade ampla e diversa. As atuais instalações físicas são fruto de diversas reformas e ampliações ao longo dos anos de atuação da unidade, quase sempre através de doações ou parceria com outros entes, como prefeituras, associações, Estado etc. Por consequência, estas modificações são realizadas muitas vezes com planejamento deficiente ou mesmo sem controle dos materiais e serviços adquiridos - muitas vezes as doações não são de caráter financeiro.

Desta forma, a plataforma foi considerada um instrumento ideal para alcançar essa comunidade de maneira mais ampla, complementando as reuniões presenciais, que, em consequência das restrições de espaço e tempo são realizadas de maneira setorial, com os diferentes públicos de maneira independente. A entidade também possui uma forte concentração de poder decisório no presidente da associação e seus auxiliares.

A plataforma seria utilizada sob o aspecto de um fórum comunitário de troca de ideias e de informação da comunidade. Sob o ponto de vista sistêmico, poderia haver a possibilidade de, mesmo com recursos bastante limitados e intervenções de pequeno porte, que as diferentes informações introduzidas pelos múltiplos atores fossem capazes de auxiliar na tomada de decisão da diretoria e da equipe de projeto. Também poderiam auxiliar em futuras tomadas de decisão, como um fórum permanente de necessidades e de direcionamentos futuros para a captação de recursos. Neste aspecto a visualização do projeto e da proposta seria fundamental para compreensão destes limites.

A plataforma foi adaptada com a solicitação de cadastro de todos os colaboradores, bem como o seu cargo/função dentro da APAE. Esta qualificação é relevante para a identificação do ponto de vista abordado pelos diferentes atores. A plataforma também ofereceu a visualização da proposta apresentada à diretoria a todos os envolvidos, como forma de complementar as informações contidas no modelo e equiparar os participantes sob o ponto de vista da disponibilidade de informações. A equipe técnica da Ático esteve disponível para participar ativamente das discussões.

O experimento encontrou algumas dificuldades e não pode ser desenvolvido conforme esperado inicialmente. A primeira delas, em relação à própria equipe interna: composta por alunos dos cursos de Arquitetura e Urbanismo e Engenharia Civil do IFSP, muito atuam na assessoria de forma voluntária, fragilizando a sua ligação e a sua disponibilidade de tempo com a Ático. Assim, prazos e metas foram estabelecidos de forma mais flexível do que o desejável. A equipe também possuía deficiência no uso dos softwares BIM, consequência do momento do curso em que os participantes se encontravam e do posicionamento tardio das disciplinas específicas de BIM na grade do curso de Arquitetura e Urbanismo. O curso de Engenharia Civil não conta com disciplinas BIM em sua grade. Assim, a qualidade do modelo BIM e, consequentemente, da visualização ficou comprometida, sendo necessário a intervenção da equipe de pesquisa para um desenvolvimento mínimo.

Por outro lado, a dinâmica com a APAE foi bastante complexa, já que há uma forte concentração do poder decisório por parte da diretoria. Esta concentração se ocorre pois além de se configurar como um trabalho voluntário, há um componente político bastante forte, pois, esta diretoria é responsável por fazer a intermediação entre os diferentes grupos de atores e a comunidade externa, inclusive com o poder público e com grupos de doadores e outros grupos de voluntários. É inegável que é necessária uma habilidade social e um carisma próprio à essa diretoria, mas ao mesmo tempo, nota-se a personalização desta gestão. Estas questões são discutidas por Chiareto (2019) e LaCruz (2017) sob os aspectos de governança, profissionalização e o seu papel na obtenção de recursos financeiro, mas podem ser extrapoladas para as dinâmicas observadas. Estas dinâmicas possuem influência em processos participativos, que demandam um compartilhamento e a realização de concessões internas com os demais atores, 


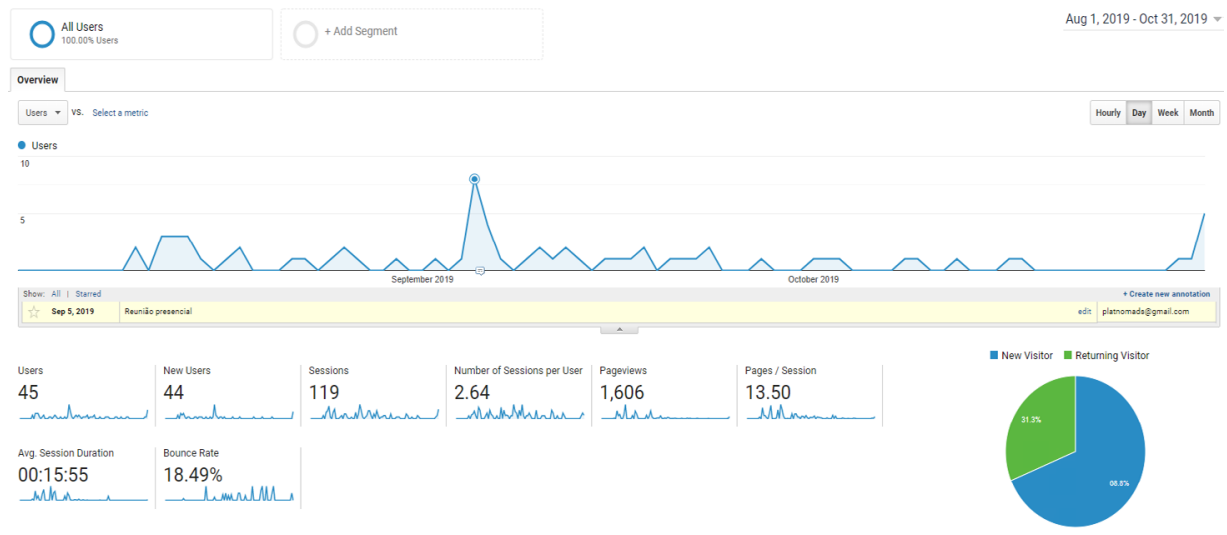

Figura 8: Acessos totais à plataforma. Notar o pico no dia 5 de setembro. Fonte: Google Analytics, 2020.

o que é conflitante com a personalização e a falta de governança observada na entidade. Assim, a equipe de projeto não obteve acesso aos colaboradores finais, ficando a cargo da diretoria efetuar a divulgação e o acompanhamento de uso da plataforma. Como pode-se verificar na figura 8 , o pico de acessos se deu somente no dia 5 de setembro, com 8 usuários - exatamente os envolvidos na reunião presencial com a diretoria. Os acessos posteriores são da própria equipe da Ático verificando a operação da plataforma.

A pequena quantidade de mensagens postadas também não se transformara em discussões embasadas. As contribuições foram dadas somente pelos próprios presentes na reunião. Mesmo a plataforma contando mais possibilidades de interação, como apoiar ou desapoiar uma mensagem, não se verificou esse uso.

A participação na plataforma foi bastante incipiente, tendo se limitado ao momento da presença da equipe em reunião de apresentação da plataforma. Verificando-se os dados de acesso, nota-se que não houve nenhum tipo de acesso após esse momento, o que evidencia um não atendimento à solicitação de transmissão do endereço da plataforma aos colaboradores e demais atores da comunidade. Esse contato foi intermediado exclusivamente pela diretoria, e, portanto, é seguro inferir que, não havendo nem mesmo acessos diversos além dos próprios pesquisadores, que simplesmente não houve uso da plataforma por falta de divulgação.

Dessa forma, o conteúdo das interações não se traduziu em contribuições significativas na plataforma, mas suscitou diversas reflexões sobre o conteúdo e a dinâmica presente, e nos procedimentos a serem adotados nas próximas ações.

\section{CONCLUSÕES}

O aplicativo aqui apresentado ainda se encontra em fase de estudos, em estado prototípico, e seu uso em situações reais de colaboração entre técnicos e não-técnicos ainda precisa ser realizado com cautela. Os experimentos realizados e outros em andamento, entretanto, produziram resultados encorajadores, indicando aceitação do aplicativo por usuários técnicos e não-técnicos, bem como uma flexibilidade de adaptação para diferentes aplicações, com requisitos e dinâmicas variados. A necessidade de se utilizar o aplicativo conjuntamente com outros instrumentos, sejam eles presenciais ou remotos, fica evidente no teor das contribuições obtidas: quanto maior a quantidade de informações qualificadas, tanto maior a produção de contribuições mais significativas e menos genéricas. Essa tendência se verifica no contraste de contribuições entre a ação JAM! e as demais.

A questão da associação entre diferentes meios de acesso à comunidade é essencial. As comunidades não são homogêneas, muito pelo contrário; essa heterogeneidade se manifesta nas personalidades e nos papéis que cada um exerce dentro dessa estrutura. Assim, acessar às lideranças é relevante, mas também identificar outros pontos de contato é essencial, ou haverá uma concentração da informação em alguns elementos, que poderão eventualmente utilizar-se dessa posição para legitimar a sua opinião individual.

A revisão das questões colocadas e a análise das ações com os outros pesquisadores envolvidos trouxeram novas reflexões tanto para o desenho e funcionamento da plataforma como para a as futuras ações necessárias.

Do ponto de vista tecnológico, o aplicativo é viável e operacional, dependendo, entretanto, da estabilidade de conexão à Internet e de melhor adaptabilidade a terminais móveis, em especial na interação com o modelo tridimensional, em telas sensíveis ao toque. Entretanto conclui-se que a possibilidade de interação com o modelo BIM pelos atores não-técnicos é viável e passível de gerar contribuições significativas no processo de projeto de obras públicas. A partir destes experimentos o aplicativo está passando por uma revisão de sua interface gráfica, buscando simplificá-la e aumentar a interatividade entre o modelo e a discussão. Também está sendo desenvolvido um acesso dinâmico aos metadados do modelo, elemento ausente nas primeiras versões do aplicativo. Estas revisões são essenciais para que possamos estruturar uma futura ação, planejada a princípio para ocorrer em abril de 2020, mas impedida pela pandemia de COVID-19 
Entendemos, por um lado, que esse esforço caminha na mesma direção das ações propostas pelo governo brasileiro para a implementação do BIM, adaptada a contextos locais. Por outro lado, a aplicação proposta nesta pesquisa também tem o papel de possibilitar e estimular o controle e o monitoramento das ações do próprio governo pela sociedade. Acreditamos, portanto, que seus recursos podem ser de interesse de vários atores, não apenas no Brasil, mas em outros países em desenvolvimento, e por isso vislumbramos a possibilidade de estabelecimento de novas parcerias de cooperação acadêmica para sua plena realização e implementação.

O aplicativo, entretanto, não possui a pretensão de substituir ou sobrepor-se aos processos de participação e controle já estabelecidos, mas de operar associado a eles, possibilitando o acréscimo de uma dimensão à participação e colaboração de não-técnicos nos processos decisórios de intervenções públicas. Não se ignora que a implementação de tais processos depende de iniciativa e de mudanças na própria estrutura e forma de operação dos órgãos oficiais - por exemplo, caso os projetos não sejam elaborados ou contratados com o uso do BIM por parte do Poder Público, não há possibilidade de interação com o modelo, requerida pelo aplicativo. Além, disso, o espaço de debates deve possuir atribuições equivalentes às de uma audiência pública, com registro das ações e atos de todos os envolvidos, sob o risco de o aplicativo tornar-se apenas um instrumento propagandístico ou de confirmação de decisões pré-definidas, o que constitui uma crítica comum aos instrumentos existentes.

Por fim, espera-se que o processo de desenvolvimento deste aplicativo possa estimular o avanço de reflexões e pesquisas sobre questões como participação e colaboração, ampliando as possibilidades do uso do BIM como gerenciador da informação, em especial, na construção da informação por públicos mais amplos, compartilhando entendimentos sobre processos de projeto e construção, e sobre demandas dos usuários e cidadãos.

\section{REFERÊNCIAS}

Aibinu, A. \& Papadonikolaki, E. (2016). BIM Implementation and Project Coordination in Design-Build Procurement.

Cheng J.C.P, Lu Q. (2015). A review of the efforts and roles of the public sector for BIM adoption worldwide. Journal of Information Technology in Construction (ITcon), Vol. 20, pg. 42-478, retrieved from: http://www.itcon.org/2015/27.

Chiareto, J. (2019). O conselho de administração e o desempenho de hospitais sem fins lucrativos brasileiros. Tese de Doutorado,
Faculdade de Economia, Administração e Contabilidade, Universidade de São Paulo, São Paulo. doi:10.11606/T.12.2019.tde-04062019-145818. Recuperado em 2020-07-08, de www.teses.usp.br

Ciribini, A. L. C.; Bolpagni, M.; Olivieri, E. (2015). An Innovative Approach to e-public Tendering Based on Model Checking. Procedia Economics and Finance, v. 21, p. 32-39.

Eastman, C; Teicholz, P.; Sacks, R; And Liston, K. (2008). BIM Handbook: A Guide to Building Information Modeling for Owners, Managers, Designers, Engineers and Contractors, John Wiley and Sons, NY.

Kassem, M.; Succar, B. (2017). Macro BIM adoption: Comparative market analysis. Automation in Construction, v. 81, p. 286-299.

LaCruz, A. J. (2017). Governança no terceiro setor: estudo em associações e fundações privadas sem fins lucrativos do segmento meio ambiente com atuação no Brasil. Tese de Doutorado, Centro de Ciências Jurídicas e Econômicas, Universidade Federal do Espírito Santo, Vitória

Melhado, S. B. (2001). Gestão, Cooperação e Integração para um Novo Modelo Voltado à Qualidade do Processo de Projeto na Construção de Edifícios. São Paulo.

Succar, B. (2009). Building information modelling framework: A research and delivery foundation for industry stakeholders. Automation in Construction, v. 18, n. 3, p. 357-375.

Succar, B., \& Kassem, M. (2015). Macro-BIM adoption: Conceptual structures. Automation in Construction, 57, 64-79. http://bit.ly/BIMPaperA8

Pita, J. V. C.; Tramontano, M. (2017). Bim and Public Administration: The Brazilian Case. In: The 22nd International Conference on Computer-Aided Architectural Design Research in Asia, Suzhou. Protocols Flows and Glitches. Hong Kong: The Association for Computer-Aided Architectural Design Research in Asia. v. 1. p. 189-198.

Pita, J. V. C.; Tramontano, M. (2019). Building Information Modeling for Participatory Decision-making Processes. In: 37th eCAADe and 23rd SIGraDi Conference, Porto. Architecture in the Age of the 4th Industrial Revolution - Proceedings of the 37th eCAADe and 23rd SIGraDi Conference. Porto: Universidade do Porto. v. 1. p. 283-292.

Wong, A. K. D., Wong, F. K. W., \& Nadeem, A. (2009). Comparative roles of major stakeholders for the implementation of BIM in various countries. Proceedings of the International Conference on Changing Roles: New Roles, New Challenges, Noordwijk Aan Zee, Holanda. 